FACTA UNIVERSITATIS

Series: Mechanical Engineering Vol. 14, No 1, 2016, pp. 1 - 19

Review article

\title{
MODELS FOR INTRALAMINAR DAMAGE AND FAILURE OF FIBER COMPOSITES - A REVIEW
}

\author{
UDC 539.4
}

\begin{abstract}
Klaus Rohwer
DLR, Institute of Composite Structures and Adaptive Systems, Braunschweig, Germany
\end{abstract}

\begin{abstract}
In order to fully exploit the potential of structures made from fiber composites, designers need to know how damage occurs and develops and under what conditions the structure finally fails. Anisotropy and inhomogeneity cause a rather complex process of damage development which may be one reason for an exceptionally large number of existing models. This paper intends to provide an overview over those models and give some hints about current developments. As such it is an updated version of a recent publication [1]. The survey is limited to laminates from unidirectional layers out of straight continuous fiber polymer composites under quasi-static loading. Furthermore, focus is laid on intralaminar damage.

Many failure models smear out the inhomogeneity between fibers and the matrix. Simply limiting each stress component separately can lead to surprisingly good results as documented in the first World-Wide Failure Exercise. Interpolation criteria consider mutual influence of normal and shear stresses, predominantly through a quadratic failure condition. Traditionally one distinguishes between interpolation criteria and physically based ones. As an important physical effect the difference between fiber failure and inter-fiber failure is considered. Furthermore, stress invariants are taken as a basis, increased shear strength under compression is accounted for, and characteristic failure modes are captured. Fibers and the matrix material are characterized by a large disparity in stiffness and strength. Micromechanical models consider this inhomogeneity but suffer from the difficulty to determine relevant material properties. Compressive strength in fiber direction has attracted special attention. However, the role of kink band formation, which is observed in the failure process, seems to be not yet fully understood.

In summary it must be concluded that despite the tremendous effort which has been put into the model development the damage and failure simulation of fiber composites are not in a fully satisfying state. That is partly due to lack of accurate and reliable test results.
\end{abstract}

Key Words: Fiber Composites, Unidirectional Layers, Strength, Failure Conditions

Received February 23, 2015 / Accepted March 10, 2015

Corresponding author: Klaus Rohwer

DLR Braunschweig, Lilienthalplatz 7, 38108 Braunschweig, Germany

E-mail: klaus.rohwer@dlr.de 


\section{INTRODUCTION}

For an efficient design the structural engineer needs to know as accurately as possible under what conditions the designated material will develop damage and finally fail. Only then is it possible to fully exploit the potential of the structure while maintaining the required safety. In any case, some information on damage and failure must be obtained by suitable tests. These tests are usually performed on coupons and aimed at determining the material strength under a specific single state of stress, be it pure tension, compression or shear. The general state of stress in a loaded structure, however, consists of several, if not all, components of the stress tensor. Thus, a criterion is needed which maps the actual state of stress to the limited number of test results.

This paper reviews different possibilities of formulating criteria and points out development tendencies limited to laminated continuous fiber-reinforced polymer composites. As an updated version of a paper previously published by the author [1] this review was prepared for and presented at the NAFEMS World Congress in San Diego, CA, in June 2015. It then was adequately formatted and modified for publication in $F U$ Mech Eng. Similar reviews have been performed earlier, for instance by Nahas [2] or Thom [3]. Since then, however, models have been developed further. In parts that is due to the tremendous increase in computational power which allows for more and more complex models. Besides, the World-Wide Failure Exercises, WWFE-I [4], -II [5] and III [6], have demonstrated deficiencies in the existing failure theories and therewith fired new developments. The large number of existing theories prohibits recognizing them all; rather only those will be assessed which in the opinion of the author have reached some level of acceptance. Furthermore, not every detail of the respective theory can be outlined; only those aspects will be referred to which the author regards important.

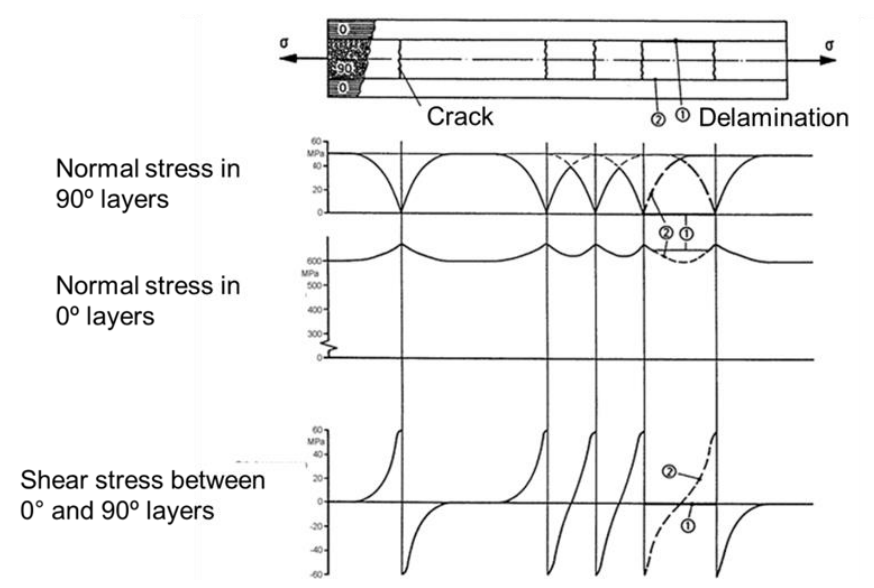

Fig. 1 Damage development

The scope of this review is focused on intralaminar fracture of laminates made from unidirectional layers which are subjected to quasi-static loading. Delaminations, woven fabrics, and effects resulting from fatigue or impact loads are not covered. Further, the material behavior after the first appearance of damage is of interest, especially for fiber 
composites. That is because in case of matrix failure the fibers are often able to carry much higher loads. A typical development of cracks and delaminations in a cross-ply laminate under axial tension is depicted in Fig. 1. It shows why the crack density is limited, finally forming a characteristic damage state.

Effects of the progressive failure of fiber composites have been extensively studied by Knight [7]. He differentiated between ply discounting approaches and continuum damage mechanics methods. Libonati and Vergani [8] have recently tested fiber composite behavior before and after failure onset using thermography. They have identified three regions: An initial region without damage, a second region where micro-damages appear which may be initiated by pre-existing defects, and a third region with an extended damage size. Considering these results, within this paper the main focus is laid on the second and third region. Different failure criteria and damage progression models will be outlined, pros and cons be mentioned, and tendencies in the development will be identified.

A vast majority of existing failure criteria is formulated in stresses, and there are good arguments to do so. Christensen [9], for instance, mentioned that such a formulation would be more suitable in order to fit with fracture mechanics or dislocation dynamics. In addition he pointed out that viscous material can fail under constant stress, but not under constant strain due to relaxation. A major point of criticism against a stress-based criterion is related to strength measurements. Usually strength is obtained as the load carrying capacity at final failure. Many tests, however, show a rather nonlinear stress-strain behavior, which is, at least in parts, due to progressive damage. There is a need to clearly define failure of composites. From comparative studies between deterministic and probabilistic analyses of cross-ply laminates under tension Sánchez-Heres et al. [10] concluded that an increased understanding is required regarding the effects of progressive matrix cracking in order to reach a safer structure.

During the design phase 'quick and dirty' methods are needed which are fast, simple to use and lead into the right direction, but do not claim to be highly accurate. Among these is the netting theory, where only the fibers are accounted for carrying loads. Quite popular is a limitation of strains to a fixed amount. Further, there is the $10 \%$ rule by Hart-Smith [11], predicting the strength and stiffness of fiber-polymer composites on the basis of simple ruleof mixtures. Though very useful, such methods will not be considered in the following.

\section{HOMOGENEOUS MODELS}

\subsection{Shape of failure envelope}

Of course fiber composites are not homogeneous; however, the overall behavior of the material can be appropriately described by smeared out properties. Also, a large number of failure models are based on the assumption of a homogeneous anisotropic material, specifying a failure envelope in stresses or strains. There is a general agreement that the failure envelope should be convex. Otherwise, unloading from a certain state of stress may indicate failure. It is under discussion, however, as to whether the failure surface should be open or closed. Christensen [9] stated: "All historical efforts to derive general failure criteria used the condition that the isotropic material would not fail under compressive hydrostatic stress", which means that the failure surface is assumed open. In 
his treaties on failure surfaces for polymeric materials Tschoegl [12] pointed at "the common sense requirement that the surface should be open in the purely compressive octant (because hydrostatic compression at reasonable pressures cannot lead to failure in the ordinary sense)". For fiber composites the situation is different. Because of the stiff fibers an external hydrostatic load causes matrix stresses which differ considerably from hydrostatic ones. Comparing theories and experiments of the WWFE-II exercise Kaddour and Hinton [13] mentioned "the diversity exhibited between the theories as to whether certain failure envelopes are 'open' or 'closed"'. However, this discrepancy should not exist, and Christensen [9] has provided reasonable arguments why fiber composites cannot sustain unlimited hydrostatic pressure.

\subsection{Non-interactive criteria}

The easiest criterion limits every stress component separately, not accounting for any interaction. Fig. 2 illustrates that in this case the failure surface is necessarily closed.

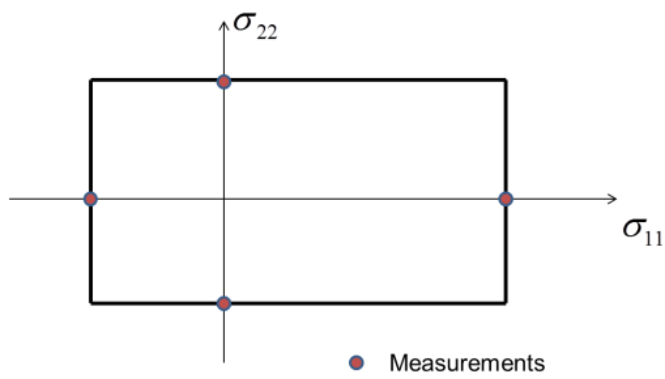

Fig. 2 Maximum stress

Astonishingly enough, this rather crude approach has been applied quite successfully by Zinoviev et al. [14] in WWFE-I. The failure criterion was supplemented by a special model characterizing the progressive damage under transverse tension and in-plane shear of a UD ply within a multidirectional laminate. This model describes the loading as linear elastic - ideal plastic, and the unloading as linear elastic with a smaller module. A comparatively favorable performance was highlighted by Hinton et al. [15]. Some discrepancies between theoretical predictions and test results Zinoviev et al. [16] traced back to the assumption about the fatal impact of ultimate transverse compressive stresses in a single ply on the failure of the whole composite laminate.

Hart-Smith [17-19] applied modified maximum strain as well as maximum stress criteria in the WWFE-I. The modification affects a truncation of the failure envelope in the biaxial tension-compression quadrant. Differences between analysis and test results were explained by deficiencies with respect to matrix-dominant failure. The maximum strain criterion in conjunction with plasticity used by Bogetti et al. [20, 21] delivered good results in the WWFE-I; the strengthening effect that appears under tri-axial loading or hydrostatic pressure, however, is obviously not well captured as has been admitted by Bogetti et al. [22]. Furthermore, Bogetti's theory predicts a completely closed failure envelope even for isotropic materials. 
Nahas [2] has referred to further non-interactive theories which to some degree account for the strength of the constituents. In general, however, these theories have not been used very often in practice. It is but the maximum strain model which because of its simplicity is still applied especially in the initial design phase.

\subsection{Interpolation criteria}

Following yield conditions for isotropic and orthotropic materials, Hoffman [23] proposed a quadratic fracture condition accounting for the difference between tensile and compressive strength in fiber and transverse directions. Based on the idea that a tensor polynomial can describe the failure surface, Tsai and $\mathrm{Wu}$ [24] came up with a similar approach. These popular failure criteria consider interactions between different components of the stress tensor. A general formulation is given in Eq. (1):

$$
\mathrm{F}_{\mathrm{ij}} \sigma_{\mathrm{i}} \sigma_{\mathrm{j}}+\mathrm{F}_{\mathrm{i}} \sigma_{\mathrm{i}}=1
$$

where $F_{i}$ and $F_{i j}$ are strength coefficients. Most of their values are easily determined from the measured strengths in fiber and transverse direction. Only the interaction terms $F_{i j}$ for $\mathrm{i} \neq \mathrm{j}$ linked to the product of two normal stress components require difficult tests under biaxial load; and these terms are important since they may indicate implausible strength levels above those in fiber direction as can be seen from Fig. 3. The interpolation criteria suffer from a further drawback. Distinguishing between fiber breakage, matrix cracks, or interface failure, is not possible by a smooth mathematical function.

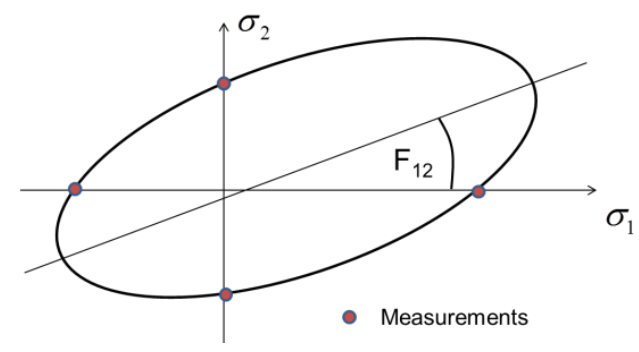

Fig. 3 Elliptic failure surface

By comparing with test results under plain stress conditions Narayanaswami and Adelman [25] concluded to rather set the terms $F_{12}$ to zero. Liu and Tsai [26] underlined that the failure surface must be closed, and they gave an overview over different possibilities for the interaction terms. Further, they have outlined a procedure for determining progressive laminate failure using reduced moduli which in the end leads to last ply failure. DeTeresa and Larsen [27] have proposed relations between the interaction terms and the strengths in fiber and transverse direction which fit to an open failure surface. A test under hydrostatic pressure has shown no damage.

There are a number of other interpolation criteria with certain inconveniences or restrictions. The criterion proposed by Norris [28] does not explicitly account for differences in tensile and compression strength; on application the user must check the sign of the different stress components and use corresponding strength values. The same 
holds for the Tsai-Hill criterion as described by Azzi and Tsai [29], which differs from the Norris criterion only in the interaction between the axial and transverse normal stress. The proposal by Yamada and Sun [30] is sometimes looked upon as a degeneration of the above mentioned criteria, a view which ignores the intention to determine the final failure of a laminate. Further, the shear strength to be used in this criterion must be determined in tests with crossply laminates leading to much higher values than those obtained from a single ply. It is also worth mentioning that Yamada and Sun stressed the need to account for statistical distributions of the strength values. The criterion by Rotem [31, 32] differentiates between failure in the fibers or in the matrix. Fiber failure (FF) is modeled by a maximum stress criterion in fiber direction with some modifications accounting for effects of transverse stresses, whereas matrix failure is predicted using a quadratic interaction of axial, transverse, and shear stresses. By means of comparing with test results, Kaddour and Hinton [13] stated that there are indications "that the theory does not discriminate adequately between initial and final failure".

Several other interpolation criteria have been mentioned by Nahas [2], which to the author's knowledge have not reached much public attention.

\subsection{Physically based criteria}

Distinguishing between interpolation criteria and physically based ones is a bit artificial and a traditional classification. Neither are the interpolation criteria free of some physical background nor are the physically based ones free of some simple interpolation aspects. There is rather a gradual transition between both the categories which makes it somewhat arbitrary where to draw the line.

In his model development, Hashin [33] pointed out that using a formulation quadratic in stresses is based on curve fitting considerations rather than on physical reasoning. $\mathrm{He}$ looked at the stress invariants and differentiated between four failure modes: tension or compression in fiber or in transverse direction. For the inter-fiber failure he mentioned the idea to hold the stresses acting at the failure plane responsible. That implies to determine the most probable crack direction which is computationally costly. Hence he settled for the quadratic formulation which leads to not fully satisfying solutions.

Building up on Hashin's original idea Puck [34, 35] formulated a criterion which yielded rather accurate results in the WWFE-I. He strictly distinguished between FF and IFF, where the latter comprises matrix cracks and fiber-matrix debonding. Puck, too, regarded the stresses in the fracture plain responsible for IFF. If the normal stress on the fracture plain is positive (tensile), then all three stress components foster the failure, whereas compressive stress increases the strength by means of internal friction. The different behavior under tension and compression requires additional material parameters which describe the inclination of the fracture master surface at zero normal stress as depicted in Fig. 4. Recommendations for these inclination parameters are provided by Puck et al. [36]. Based on Puck's model the strength degradation of laminates which suffer from an IFF within a certain layer was investigated by Knops and Bögle [37]. Also the German engineering guideline [38] regarding the analysis of components from fiber reinforced plastics relies on Puck's failure criterion. Dong et al. [39] complemented Puck's theory by adding effects of ply thickness and ply angles of neighboring laminae. 


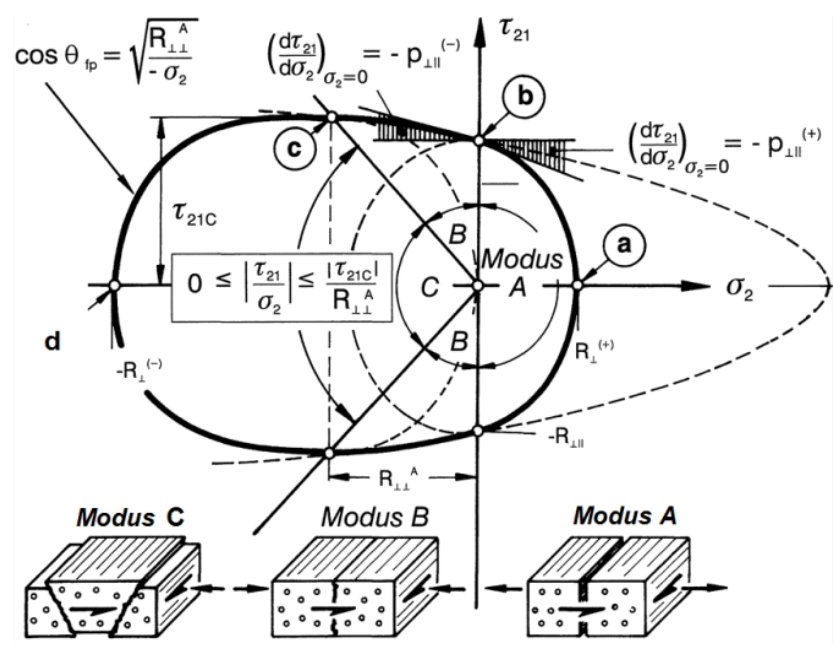

Fig. 4 Inter-fiber failure after Puck [34]

The failure mode concept (FMC) as set up by Cuntze and Freund [40] aimes at capturing the behavior of five different failure modes. Based on stress invariants the model provides one failure condition each for two FF modes and three IFF modes. Corresponding to Puck's inclination parameters two curve parameters are to be determined by multi-axial tests. Possible interactions between failure modes are accounted for by a probabilistically based series spring model approach. The FMC was subsequently improved by Cuntze [41, 42]. In connection with the behavior of isolated and embedded laminas special emphasis is put on the difference between the onset of failure and the final failure of composite laminates. Furthermore, Cuntze [43] carefully examined the tests provided for the WWFE-II and after certain corrections obtained rather good agreements.

At NASA Langley Research Center, Dávila et al. [44] have proposed failure criteria for fiber composite laminates under plane stress conditions which were extended to threedimensional stress states by Pinho et al. [45] and eventually improved with respect to matrix compression failure by Pinho et al. [46]. As with Hashin's [33] approach the failure model considers four different scenarios: tension and compression in fiber and transverse direction. For compression in fiber direction the effect of fiber undulation is regarded. Nali and Carrera [47] compared this approach against some interpolation criteria for planestress problems and found good agreement with test results.

In a detailed analysis Catalanotti et al. [48] described certain pitfalls of existing 3D failure criteria. They pointed to the requirement of using in situ strength properties in order to account for the ply thickness effect. However, by means of micromechanical analysis, Herráez et al. [49] found that strength must be independent of ply thickness. The pitfalls could be avoided by an improved criterion for transverse matrix failure. Longitudinal tension failure is predicted using a maximum strain criterion, and longitudinal compression failure accounts for fiber kinking. Building on this proposal and on the three-dimensional plasticity model for composite laminates developed by Vogler et al. [50] Camanho et al. [51] formulated new criteria where transverse failure and kinking models are invariantbased. For validation in case of complex three-dimensional stress states computational micromechanics turned out to be a useful tool. 


\section{DAMAGE MECHANICS APPROACH}

Damage mechanics does not provide conditions at which a certain type of damage occurs; rather, it uses internal variables to describe the progressive loss of rigidity due to damage of material. An example is given in Eqs. (2a) to (2d), where $d^{\prime}$ and $d$ denote the damage variables characterizing the behavior after initial damage under transverse tension and in-plane shear, respectively:

$$
\begin{gathered}
\varepsilon_{11}=\frac{\sigma_{11}-v_{12} \sigma_{22}}{E_{11}} \\
\text { if } \sigma_{22} \geq 0 \text { (tension): } \quad \varepsilon_{22}=\frac{\sigma_{22}}{E_{2}\left(1-d^{\prime}\right)}-\frac{v_{12}}{E_{2}} \sigma_{11} \\
\text { if } \sigma_{22} \leq 0 \text { (compression): } \quad \varepsilon_{22}=\frac{\sigma_{22}-v_{12} \sigma_{11}}{E_{2}} \\
\varepsilon_{12}=\frac{\sigma_{12}}{2 G_{12}(1-d)}
\end{gathered}
$$

Ladevèze and Le Dantec [52] have applied damage mechanics to set up a model which describes ply-wise matrix microcracking and fiber/matrix debonding. Reaching the maximum mean stress or a maximum of the load-deflection curve specifies the laminate failure. This model was adopted by Payan and Hochard [53] to study the behavior of UD laminates from carbon fiber-reinforced plastics (CFRP) under shear and transverse tension. They found elastic behavior up to brittle failure in fiber direction, and gradient loss of rigidity due to damage under shear and transverse tension. Based on these results they developed a model which covers the damage state by means of two scalar-damage variables describing the loss of rigidity under shear and transverse tension loading, respectively. The model has proven to be valid for a "diffuse damage" phase where micro-cracks occur and it is limited to the first intralaminar macro-crack. Hochard et al. [54] have further extended the model to problems with stress concentrations. The approach is based on a Fracture Characteristic Volume which is a cylinder defined at the ply scale where the average stress is calculated and compared to the maximal strength of the material.

Barbero and de Vivo [55] presented a damage mechanics approach where the damage surface has the shape of the Tsai-Wu [24] criterion. But it goes beyond a failure criterion by "identifying a damage threshold, hardening parameters for the evolution of damage, and the critical values of damage". These parameters are all related to known material properties but not directly measurable (cf. Barbero and Cosso [56]).

Van Paepegem et al. [57] performed tension tests with $[ \pm 45]_{2 \mathrm{~s}}$ laminates and used the results to determined one parameter each for shear modulus degradation and the accumulation of permanent shear strain. The same authors [58] applied these parameters to a mesomechanical model which did not account for time-dependent effects like strain rate or viscoelasticity. Nevertheless, they were able to describe the nonlinear behavior up to failure of glass-fiber reinforced composite laminates under various loads rather accurately. Time and temperature dependency of fracture strengths both in tension and compression 
were thoroughly studied by Miyano et al. [59]. They found out that the strength master curves can be set up successfully by using the reciprocation law between time and temperature.

A majority of models for damage progression in laminates are based on the unrealistic assumption that each ply behaves independently of its neighbors. In order to account for the interaction between adjacent layers Williams et al. [60] developed a continuum damage approach for sub-laminates. Therewith it is not intended to predict details of damage at the ply level, rather to capture the sub-laminate's overall response. The idea was further upgraded by Forghani et al. [61] considering several aspects specific for damage progression in multidirectional composite laminates and applied to the open hole problems of the WWFE-III. The open hole tension strength of composite laminates was also studied by Ridha et al. [62]. They found a significant interaction between delamination and in-plane damage, so that neglecting delamination would overestimate strength.

Frizzell et al. [63] developed a numerical method based on continuum damage mechanics that is capable of describing sub-critical damage and catastrophic failure mechanisms in composite laminates. They proposed a "pseudo-current" damage evaluation approach which avoids convergence problems even for complex damage mechanisms.

\section{INHOMOGENEOUS MODELS}

\subsection{Strength of constituents}

Fibers and the matrix material are characterized by a large disparity in stiffness and strength. Though smeared out in the models reviewed above, this fact certainly influences the failure process and thus it is reflected in certain features. In this section, approaches will be discussed which account for the inhomogeneity in one way or the other. To this end strength properties of the constituents are needed. Measuring them, however, encounters difficulties.

Resin strengths are typically measured in appropriate tests with neat material. An overview over models with relevance to resin failure was given by Fiedler et al. [64]. These authors have proven that the type of resin failure depends not only on the material itself but also on the state of stress. They found out that "ductility is a function of the amount of tri-axiality and explains why ductile polymers behave brittle when used as a matrix in fiber reinforced composites". Such an effect was detected and analyzed already by Asp et al. [65]. On the other hand, Pae [66] has found that brittle epoxy develops yielding when hydrostatic pressure is superimposed on the loading. Because of these intricacies, properties determined from tests with neat resin must be handled with caution when used in a micromechanical failure analysis.

Shear strength of the fiber-matrix interface can be obtained from fiber pullout or pushout tests. Kerans and Parthasarathy [67] proposed a procedure for extracting interface parameters from the test data. An analytical model describing the fiber pushout was developed by Liang and Hutchinson [68]. More involved is the determination of interface strength under transverse loads since secondary transverse stress perpendicular to the primary transverse compression affects the threat of fiber-matrix interface fracture. Correa et al. [69] found out that secondary tensile stress increases the risk whereas compression decreases it. 
Measuring fiber tensile strength seems to be a relatively easy task. When performing the tests, however, it becomes apparent that the results depend on the specimen length. The longer the specimen, the lower is the measured tensile strength. Even more questionable is the determination of the compressive strength in fiber direction. In a composite the compressed fibers usually do not suffer a material failure but a loss of stability. Thus the composite strength limit will depend on the matrix properties. Wang et al. [70] have proposed a tensile recoil method to obtain the fiber compressive strength and a microbond fiber pull-out test for the interface shear strength.

\subsection{Models with some effect of inhomogeneity}

In this section, approaches will be discussed which to some extent consider inhomogeneity but still show relations to the homogeneous models mentioned above. This evidently holds for the discrete damage mechanics approach as proposed by Barbero and Cortes [71]. By means of fracture mechanics applied to the inhomogeneous material they determined parameters for stiffness reduction of the homogenized structure. Barbero and Cosso [56] showed that this approach can be successfully applied to model damage and failure of laminates from CFRP.

Inhomogeneity plays an important role in tests of inplane shear strength. There is as yet a deep disagreement as how to obtain reliable values. Odegard and Kumosa [72] have thoroughly investigated the standard Iosipescu test with $0^{\circ}$ specimens as well as the $10^{\circ}$ off-axis test. They found good agreement only if the Iosipescu tests are accompanied by fully nonlinear finite element analyses including plasticity and premature cracks, and the $10^{\circ}$ off-axis test must be carefully machined to avoid micro-crack at the specimen edges. The growth of cracks in a UD fiber reinforced lamina was modeled by Cahill et al. [73]. By means of the extended finite element method (XFEM) for heterogeneous orthotropic materials where material interfaces are present as well as a modified maximum hoop stress criterion for determining the direction of the crack propagation at each step they found out that for a material with a large stiffness rate between fiber and transverse direction the crack will propagate along the fiber direction, regardless of the specimen geometry, loading conditions or presence of voids. Matrix cracking and fiber-matrix debonding seem to impair each other. By means of shear load Nouri et al. [74] generated fiber-matrix debonding and observed its effect on crack density under transverse load. The authors developed a modified transverse cracking toughness model.

In order to accomplish the tasks put forward in the WWFE-I, Gotsis et al. [75] used the computer code ICAN by Murthy and Chamis [76], which determines material properties using micromechanics and accounts for laminate attributes like delamination or free edge effect. In addition to the maximum stress criterion a modified distortion energy failure criterion determines the ply failure. Comparison with the test results as provided by Gotsis et al. [77] revealed reasonable results in cases of fiber dominated failure, but rather large discrepancies when matrix failure was predominant. Analysis methods were further improved to a full hierarchical damage tracking and applied in the WWFE-III challenge by Chamis et al. [78]. Therewith constituent properties determined by inverse model application were used for the micromechanical analysis part. 


\subsection{Tensile strength in fiber direction}

Some effort was put on developing models for the determination of tensile strength in fiber direction from constituent properties. Considering the standard composite design with an extension to failure of the matrix much higher than that of the fibers, the composite failure stress can be roughly estimated by the rule of mixture from the failure stress of the fiber and the matrix stress at fiber rupture. However, that does neither account for varying fiber strength along each single fiber nor for strength variation between fibers. A number of hypotheses accounting for these variations have been proposed, e.g. by Rosen [79] and Zweben [80], but results from their application are not very convincing. More recent developments along this line are the global load sharing scheme by Curtin [81], the simultaneous fiber-failure model by Koyanagi et al. [82] and statistical models for fiber bundles in brittle-matrix composites by Lamon [83].

\subsection{Compressive strength in fiber direction}

Models for compressive strength in fiber direction were first set up by studying the buckling of fibers on an elastic support. Depending on the fiber volume fraction Dow and Rosen [84] differentiated between an extension and a shear failure mode. Their results, however, proposed too high strength values. Xu and Reifsnider [85] extended the model by assuming slippage between fibers and the matrix over certain regions and therewith determined a good agreement with test results. Following a thorough review of the models developed until then Lo and Chim [86] proposed to improve the microbuckling concept by considering transverse isotropy of the fibers and the effects of resin Young's modulus, fiber misalignment, a weak fiber matrix interface as well as voids. They also pointed out that in case the strain to failure of the fibers is reached prior to buckling, then the compressive strength should be determined by the rule of mixture between fibers and the matrix. The effect of fiber misalignment and resultant kinking was studied by Budiansky and Fleck [87]. Their model, however, was not able to predict the width of the kink band and its inclination. Micromechanical analyses of the kink band formation after fiber buckling including the effect of fiber misalignment were performed by Kyriakides et al. [88] and by Jensen and Christoffersen [89]. After a thorough derivation of a stress based model for fiber kinking, Ataabadi et al. [90] pointed to certain drawbacks of the model. In order to alleviate them they proposed an improvement based on strains and used it to predict the compressive strength depending on the fiber misalignment. On validating this strain based model against test results Ataabadi et al. [91] found that for specimens with an off-axis angle greater than $0^{\circ}$ this model can predict the compressive strength of UD laminated composites with acceptable accuracy. Gutkin et al. [92, 93] distinguished between two different failure mechanisms: shear-driven fiber compressive failure and kinking/splitting. Similar to that approach Prabhakar and Waas [94] studied the interaction of kinking and splitting by means of a 2D finite element model. With a perfect interface the stress-strain curve shows a typical instability behavior with a sharp peak and a snap-back branch afterwards. Since local strains then exceeded the strain to failure for polymer matrix material discrete cohesive zone elements were applied at the fiber-matrix interface. It turned out that it is important to know especially the mode-II cohesive strength of the interface in order to determine the compressive strength and failure mode of UD laminates accurately. The same authors [95] further extended the micromechanical model of failure under compression to multidirectional laminates considering delaminations. That allowed studying the effect of stacking sequence on 
the compressive strength. Mishra and Naik [96] used the inverse micromechanical method to calculate fiber properties and applied them to determine the compressive strength for a composite with a different fiber volume fraction. A formulation capable of obtaining the maximum compression stress, and the post-critical performance of the material once fiber buckling has taken place was proposed by Martinez and Oller [97]. Dharan and Lin [98] questioned the role of initial fiber waviness and kink band formation on the compressive strength in fiber direction. Like Lo and Chim [86] did earlier, they rather extended the micro-buckling model of Dow and Rosen [84] by accounting for an interface layer around the fibers, the thickness and shear modulus of which have to be adjusted to test results. Zidek and Völlmecke [99] used a simple analytical model introduced by Wadee et al. [100]. They improved it by accounting for initial fiber misalignment. Furthermore this model allows for predicting the kink band inclination angle.

Obviously, there is not a generally accepted view yet as to whether kink band formation is a failure mode that limits the compressive strength or rather a secondary effect which appears after buckling.

\subsection{Normal strength in transverse direction}

Tensile and compressive strength in transverse direction was studied by Asp et al. [101, 102]. They used a micromechanical approach with a representative volume element, which thereafter became more and more popular. Not accounting for fiber-matrix debonding they have found that the fiber modulus has a significant effect on the failure caused by cavitation in the matrix. This brittle failure occurred earlier than yielding. A thin interphase of a rubbery material improves the transverse failure properties. Tensile and compressive strength with perfect fiber-matrix adhesion on the one hand and complete debonding on the other hand was compared by Carvelli and Corigliano [103]. Assuming periodicity for rather small fiber volume fraction they determined finite strength under biaxial tension only with debonded interfaces. Transverse tensile failure behavior of fiber-epoxy systems was also studied by Cid Alfaro et al. [104]. They pointed to a strong influence of the relative strength of the fiber-epoxy interface and the matrix. Vaughan and McCarthy [105] found out that in case of a strong fiber-matrix interface residual thermal stresses improve the transverse tensile strength.

\subsection{Shear strength}

Several authors applied micromechanical means for analyzing fiber composite shear strength. King et al. [106] determined the composite transverse shear strength, mainly to predict the effect of fiber surface treatment and sizing on the interfacial bond strength. They found out that the predicted composite shear strength strongly depends upon the type of matrix and the interface strength, and is not significantly dependent on the fiber properties. Axial tension tests on $\left[ \pm 45^{\circ}\right]_{\mathrm{s}}$ laminates are often used to determine the composite shear stress-strain response. Comparing the shear behavior of CFRP with epoxy and PEEK matrix, Lafarie-Frenot and Touchard [107] determined a pronounced plastic deformation but no visible damage in the low loading range. Higher load levels led to increased damage in the epoxy matrix and early failure whereas the PEEK material exhibited even larger plastic deformation in connection with a considerable change of the fiber angle. The detectability of microcracks, however, may have been limited due to the fact that the contrast agent for X-ray inspection was applied to the free edges only. On the 
contrary, by means of tests with dog bone specimens and micromechanical analyses $\mathrm{Ng}$ et al. [108] found out that it is micro-cracking rather than plasticity, which brings about the observed nonlinear softening. In V-notched rail shear tests on cross-ply laminates reinforced with HS fibers Totry et al. [109] did not find any evidence of damage in the MTM57 epoxy resin after a shear deformation of $25 \%$. If the same resin was reinforced with HM fibers, however, intraply damage occurred at $\gamma_{12}=15 \%$. It seems rather unlikely that such large strains can appear without any damage. For laminates out of glass-fiber reinforced epoxy Giannadakis and Varna [110] determined viscoelasticity and viscoplasticity as the major cause for nonlinearity, whereas the effect of microdamage is very small. Until verifying what really happens in the shear tests it seems to be unreasonable to invest further effort into modeling it.

\subsection{Strength under combined loading}

Micromechanics were also used for strength prediction under combined loading. The influence of interface strength on the composite behavior under out-of-plane shear and transverse tension was studied by Canal et al. [111]. They concluded that homogeneous models like those proposed by Hashin or Puck cannot accurately predict the failure surface. Transverse compression and out-of-plane shear was analyzed by Totry et al. [112], which led to the finding that interface decohesion must be taken into account for composites in matrix-dominated failure modes. Also, for transverse compression and longitudinal shear Totry et al. [113] discovered that the interface strength plays an important role for the composite strength. Fig. 5 shows some of their results which compare quite well with the tests, especially the strength increase due to internal friction comes out nicely.

Ha et al. [114] proposed a micromechanics based model which used the maximum stress criterion for FF, a modified von Mises yield criterion for matrix failure and a simple quadratic criterion for failure of the fiber-matrix interface. In order to simulate the tasks of the WWFE-II Huang et al. [115] complemented these criteria with a progressive damage model taking care of the nonlinear matrix behavior. A damage factor of 0.4 was assumed for final rupture of the damaged material. Huang et al. [116] further adapted the approach to the test results by using a quadratic FF criterion, a fiber kinking model, and a reduction of stress amplification factors for inplane shear terms. Melro et al. [117, 118] developed an elasto-plastic damage model suitable for epoxy matrix material which accounts for different behavior under transverse tension, transverse compression, and longitudinal as well as transverse shear.
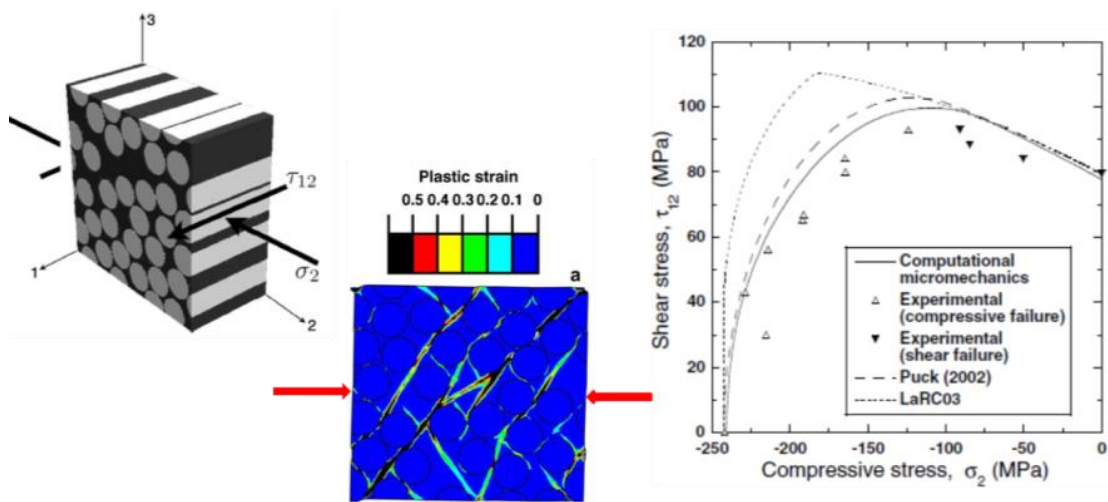

Fig. 5 Micromechanic strength analysis after Troty et al. [113] 


\section{CONCLUSIONS AND OUTLOOK}

Considerable effort has been put into the development of suitable models to reliably predict damage and failure of fiber composites. In spite of the inhomogeneity of the material homogeneous models were first choices for quite some time. They have developed from simple maximum stress or strain criteria via interpolation criteria to physically based ones. On looking at the frequency of publications in this field the development seems to have passed the top. There are quite a number of them available now. What is missing, however, is a reliable statement as to which one should be applied in the respective case at hand.

Damage mechanics accounts for the residual strength after initial damage. In general that is done by stiffness reduction smearing out local effects and therewith simulating a material nonlinearity of the affected layer. There are indications that interactions between adjacent layers can have a considerable influence on the laminate strength, which also can be accounted for by means of damage mechanics models.

Closer to the behavior of fiber composites are heterogeneous models. Talreja [119] has carefully analyzed ambiguities and uncertainties in classical failure predictions and provided remedies to overcome them, including a comprehensive analysis strategy. Chowdhury et al. [120] have compared the reliability of matrix failure prediction between criteria at the lamina level and a micromechanical approach and found out that the latter is more accurate. The greater computational effort required with heterogeneous models is no longer a major handicap thanks to the rapid increase of computational power and storage capacity. It is more the difficulty to determine relevant material properties. That especially holds if the model considers an interface layer between fibers and the matrix. Inverse methods cannot be considered as the general solution to that problem since they require the choice of a micromechanical model in the first place. Compressive strength in fiber direction has attracted special attention. However, the role of kink band formation, which is observed in the failure process, seems to be not thoroughly understood.

All in all, it must be concluded that models for predicting fiber composite damage and failure have not yet reached a fully satisfying state. For now and in the foreseeable future virtual testing of fiber composites can be suitably applied in the initial design phase and serve as a useful supplement during structural qualification. But models need further improvement before tests on real structures can be fully replaced by simulations.

Acknowledgements: This work was first presented and published at the NAFEMS World Congress 2015, in San Diego, and was adequately modified and formatted for publication in FU Mech Eng.

\section{REFERENCES}

1. Rohwer, K., 2015, Predicting fiber composite damage and failure, J Compos Mater, 49, pp. 2673-2683.

2. Nahas, M.N., 1986, Survey of failure and post-failure theories of laminated fiber-reinforced composites, J Compos Technol Res, 8, pp. 138-153.

3. Thom, H., 1998, A review of the biaxial strength of fibre-reinforced plastics, Compos A, 29A, pp. 869-886.

4. Hinton, M.J., Kaddour, A.S., Soden, P.D., (Eds.), 2004, Failure criteria in fibre reinforced polymer composites: The World-Wide Failure Exercise, Oxford, UK: Elsevier Science Ltd.

5. Kaddour, A.S. and Hinton M.J., 2013, Maturity of 3D failure criteria for fibre-reinforced composites: Comparison between theories and experiments: Part B of WWFE-II, J Compos Mater, 47, pp. 925-966. 
6. Kaddour, A.S., Hinton, M.J., Smith, P.A., Li, S., 2013, The background to the third world-wide failure exercise, J Compos Mater, 47, pp. 2417-2426.

7. Knight, N.F. Jr., 2006, User-defined material model for progressive failure analysis, NASA CR-2006214526, Washington DC.

8. Libonati, F. and Vergani, L., 2013, Damage assessment of composite materials by means of thermographic analyses, Compos B, 50, pp. 82-90.

9. Christensen, R.M., http://www.failurecriteria.com (accessed 16 Oct 2014).

10. Sánchez-Heres, L.F., Ringsberg, J.W., Johnson, E., 2013, Study on the possibility of increasing the maximum allowable stresses in fibre-reinforced plastics, J Compos Mater, 47, pp. 1931-1941.

11. Hart-Smith, LJ., 2002, Expanding the capabilities of the Ten-Percent Rule for predicting the strength of fibre-polymer composites, Compos Sci Technol, 62, pp.1515-1544.

12. Tschoegl, N.W., 1971, Failure surfaces in principle stress space, J Polym Sci C Polym Sympos, 32, pp. 239-267.

13. Kaddour, AS., Hinton, M.J., 2013, Maturity of 3D failure criteria for fibre-reinforced composites: comparison between theories and experiments: Part B of WWFE-II, J Compos Mater, 47, pp. 925-966.

14. Zinoviev, P.A., Grigoriev S.V., Lebedeva O.V., Tairova, L.P.., 1998, The strength of multilayered composites under a plane-stress state, Compos Sci Technol, 58, pp. 1209-1223.

15. Hinton, M.J., Kaddour, A.S., Soden. P.D., 2004, A further assessment of the predictive capabilities of current failure theories for composite laminates: comparison with experimental evidence, Compos Sci Technol, 64, pp. 549-588.

16. Zinoviev, P.A., Lebedeva, O.V., Tairova, L.P., 2002, A coupled analysis of experimental and theoretical results on the deformation and failure of composite laminates under a state of plane stress, Compos Sci Technol, 62, pp.1711-1723.

17. Hart-Smith, L.J., 1998, Predictions of the original and truncated maximum-strain failure models for certain fibrous composite laminates, Compos Sci Technol, 58, pp. 1151-1178.

18. Hart-Smith, L.J., 1998, Predictions of a generalized maximum-shear-stress failure criterion for certain fibrous composite laminates, Compos Sci Technol, 58, pp. 1179-1208.

19. Hart-Smith, L.J., 2002, Comparison between theories and test data concerning the strength of various fibre-polymer composites, Compos Sci Technol, 62, pp. 1591-1618.

20. Bogetti, T.A., Hoppel, C.P.R., Harik, V.M, Newill, J.F., Burns, B.P., 2004, Predicting the nonlinear response and progressive failure of composite laminates, Compos Sci Technol, 64, pp. 329-342.

21. Bogetti, T.A., Hoppel, C.P.R., Harik V.M., Newill, J.F., Burns, B.P., 2004, Predicting the nonlinear response and failure of composite laminates: correlation with experimental results, Compos Sci Technol, 64, pp. $477-485$.

22. Bogetti, T.A., Staniszewski, J., Burns, B.P., Hoppel, C.P.R., Gillespie, J.W.Jr., Tierney, J., 2012, Predicting the nonlinear response and progressive failure of composite laminates under triaxial loading: correlation with experimental results, J Compos Mater, 47, pp. 793-804.

23. Hoffman, O., 1967, The brittle strength of orthotropic materials, J Compos Mater, 1, pp. $200-206$.

24. Tsai, S.W., Wu, E.M., 1971, A general theory of strength for anisotropic materials, J Compos Mater, 5 , pp. 58-80.

25. Narayanaswami, R., Adelman, H.M., 1977, Evaluation of the tensor polynomial and Hoffman strength theories for composite materials, J Compos Mater, 11, pp. 366-377.

26. Liu, K-S., Tsai, S.W., 1998, A progressive quadratic failure criterion for a laminate, Compos Sci Technol, 58, pp. 1023-1032.

27. DeTeresa, S.J., Larsen, G.J., 2003, Reduction in the number of independent parameters for the Tsai-Wu tensor polynomial theory of strength for composite materials, J Compos Mater, 37, pp. 1769-1785.

28. Norris, C.B., May 1962, Strength of orthotropic materials subjected to combined stresses. Forest Products Laboratory, Report 1816, Madison, WI.

29. Azzi. V.D., Tsai, S.W., 1965, Anisotropic strength of composites, Exp Mech, 5, pp. 283-288.

30. Yamada, S.E., Sun, C.T., 1978, Analysis of laminate strength and its distribution, J Compos Mat, 12, pp. 275-284.

31. Rotem, A., 1998, Prediction of laminate failure with the Rotem failure criterion, Compos Sci Technol, 58, pp. 1083-1094.

32. Rotem, A, 2012, The Rotem failure criterion for fibrous laminated composite materials: three-dimensional loading case, J Compos Mater, 46, pp. 2379-2388.

33. Hashin, Z., 1980, Failure criteria for unidirectional fiber composites, J Appl Mech, 47, pp. 329-334. 
34. Puck, A., 1996, Festigkeitsanalyse von Faser-Matrix-Laminaten: Modelle für die Praxis, München, Wien: Hanser.

35. Puck, A., Schürmann, H., 1988, Failure analysis of FRP laminates by means of physically based phenomenological models, Compos Sci Technol, 58, pp. 1045-1067.

36. Puck, A., Kopp, J., Knops, M., 2002, Guidelines for the determination of the parameters in Puck's action plane strength criterion, Compos Sci Technol, 62, pp. 371-378.

37. Knops, M., Bögle, C., 2006, Gradual failure in fibre/polymer laminates, Compos Sci Technol, 66, pp. 616-625.

38. Verein Deutscher Ingenieure (VDI), 2006, Development of FRP components (fibre-reinforced plastics) analysis, Part 3., Berlin, Beuth Verlag,

39. Dong, H., Wang, J., Karihaloo, B.L., 2014, An improved Puck's failure theory for fibre-reinforced composite laminates including the in situ strength effect, Compos Sci Technol, 98, pp. 86-92.

40. Cuntze, R.G., Freund, A., 2004, The predictive capability of failure mode concept-based strength criteria for multidirectional laminates, Compos Sci Technol, 64, pp. 343-377.

41. Cuntze, R.G., 2006, Efficient 3D and 2D failure conditions for UD laminae and their application within the verification of the laminate design, Compos Sci Technol, 66, pp. 1081-1096.

42. Cuntze, R., 2012, The predictive capability of failure mode concept- based strength conditions for laminates composed of unidirectional laminae under static triaxial stress states, J Compos Mater, 46, pp. 2563-2594.

43. Cuntze, R.G., 2012, Comparison between experimental and theoretical results using Cuntze's 'failure mode concept" model for composites under triaxial loadings-Part B of the second world-wide failure exercise, J Compos Mater, 47, pp. 893-924.

44. Dávila, C.G., Camanho, P.P., Rose, C.A., 2005, Failure criteria for FRP laminates, J Compos Mater, 39(4), pp.323-345.

45. Pinho, S.T., Dávila, C.G., Camanho P.P. Iannucci, L., Robinson, P., 2005, Failure models and criteria for FRP under in-plane or three-dimensional stress states including shear non-linearity, NASA/TM2005-213530, Hampton, VA 23681.

46. Pinho, S.T., Iannucci, L., Robinson, P., 2006, Physically-based failure models and criteria for laminated fibrereinforced composites with emphasis on fibre kinking: Part I: development, Compos A, 37, pp. 63-73.

47. Nali, P., Carrera, E., 2012, A numerical assessment on two-dimensional failure criteria for composite layered structures, Compos B, 43, pp. 280-289.

48. Catalanotti, G., Camanho, P.P., Marques, A.T., 2013, Three-dimensional failure criteria for fiber-reinforced laminates, Compos Struct, 95, pp. 63-79.

49. Herráez, M., Mora, D., Naya, F. Lópes, C.S., González, C., LLorca J., 2015, Transverse cracking of cross-ply laminates: A computational micromechanics perspective, Compos Sci Technol, 110, pp. 196-204

50. Vogler, M., Rolfes, R., Camanho, P.P., 2013, Modeling the inelastic deformation and fracture of polymer composites - Part I: plasticity model, Mech Mater, 59, pp. 50-64.

51. Camanho, P.P., Arteiro, A., Melro A.R. Catalanotti, G., Vogler, M., 2015, Three-dimensional invariantbased failure criteria for fibre-reinforced composites, Int J Solids Struct, 55, pp. 92-107.

52. Ladeveze, P., Le Dantec, E., 1992, Damage modelling of the elementary ply for laminated composites, Compos Sci Technol, 43, pp. 257-267.

53. Payan, J., Hochard, C., 2002, Damage modelling of laminated carbon/epoxy composites under static and fatigue loadings, Int J Fatigue, 24, pp. 299-306.

54. Hochard, C., Lahellec, N., Bordreuil, C., 2007, A ply scale non-local fibre rupture criterion for CFRP woven ply laminated structures, Compos Struct, 80, pp. 321-326.

55. Barbero, E.J., de Vivo, L., 2001, A constitutive model for elastic damage in fiber-reinforced PMC laminae, Int J Damage Mech, 10, pp. 73-93.

56. Barbero, E.J., Cosso, F.A., 2014, Determination of material parameters for discrete damage mechanics analysis of carbon-epoxy laminates, Compos B, 56, pp. 638-646.

57. Van Paepegem, W., De Baere, I., Degrieck, J., 2006, Modelling the nonlinear shear stress-strain response of glass fibre-reinforced composites. Part I: experimental results, Compos Sci Technol, 66, pp. 1455-1464.

58. Van Paepegem, W., De Baere, I., Degrieck, J., 2006, Modelling the nonlinear shear stress-strain response of glass fibre-reinforced composites. Part II: model development and finite element simulations, Compos Sci Technol, 66, pp. 1465-1478.

59. Miyano, Y., Kanemitsu, M., Kunio, T., Kuhn, H.A., 1986, Role of matrix resin on fracture strengths of unidirectional CFRP, J Compos Mater, 20, pp. 520-538.

60. Williams, K.V., Vaziri, R., Poursartip, A., 2003, A physically based continuum damage mechanics model for thin laminated composite structures, Int J Solids Struct, 40, pp. 2267-2300. 
61. Forghani, A., Zobeiry, N., Poursartip, A., Vaziri, R., 2013, A structural modelling framework for prediction of damage development and failure of composite laminates, J Compos Mater, 47, pp. 2553-2573.

62. Ridha, M., Wang, C.H., Chen, B.Y., Tay, T.E., 2014, Modelling complex progressive failure in notched composite laminates with varying sizes and stacking sequences, Compos A, 58, pp. 16-23.

63. Frizzell, R.M., McCarthy, M.A., McCarthy, C.T., 2014, Numerical method to control high levels of damage growth using an implicit finite element solver applied to notched cross-ply laminates, Compos Struct, 110, pp. 51-61.

64. Fiedler, B., Hojo, M., Ochiai, S., Schulte, K., Ando, M., Failure behavior of an epoxy matrix under different kinds of static loading, Compos Sci Technol, 61, pp. 1615-1624.

65. Asp, L.E., Berglund, L.A., Talreja, R., 1996, A criterion for crack initiation in glassy polymers subjected to a composite-like stress state, Compos Sci Technol, 56, pp. 1291-1301.

66. Pae, K.D., 1996, Influence of hydrostatic pressure on the mechanical behavior and properties of unidirectional, laminated, graphite-fiber/ epoxy-matrix thick composites, Compos B, 27B, pp. 599-611.

67. Kerans, R.J., Parthasarathy, T.A., 1991, Theoretical analysis of the fiber pullout and pushout test, J Am Ceram Soc, 74: 1585-1596.

68. Liang, C., Hutchinson, J.W., 1993, Mechanics of the fiber pushout test, Mech Mater, 14, pp. 207-221.

69. Correa, E., París, F., Mantič, V., 2014, Effect of a secondary transverse load on the inter-fibre failure under compression, Compos B, 65, pp. 57-68

70. Wang, X.J., Francis, B.A.P., Chia, E.S.M., Zheng, L., Yang, J., Joshi, S.C. Chen, Z., 2015, Mechanical and interfacial properties characterisation of single carbon fibres for composite applications, Exp Mech, 55, pp. 1057-1065.

71. Barbero, E.J., Cortes, D.H., 2010, A mechanistic model for transverse damage initiation, evolution, and stiffness reduction in laminated composites, Compos B, 41, pp. 124-132.

72. Odegard, G., Kumosa, M., 2000, Determination of shear strength of unidirectional composite materials with the Iosipescu and $10^{\circ}$ off-axis shear tests, Compos Sci Technol, 60, pp. 2917-2943.

73. Cahill, L.M.A., Natarajan, S., Bordas, S.P.A., O’Higgings, R.M., McCaerthy, C.T., 2014, An experimental/numerical investigation into the main driving force for crack propagation in unidirectional fibre-reinforced composite laminae, Compos Struct, 107, pp. 119-130.

74. Nouri, H., Lubineau, G., Traudes, D., 2013, An experimental investigation of the effect of shear-induced diffuse damage on transverse cracking in carbon-fiber reinforced laminates, Compos Struct, 106, pp. 529-536.

75. Gotsis, P.K., Chamis, C.C., Minnetyan, L., 1998, Prediction of composite laminate fracture: micromechanics and progressive fracture, Compos Sci Technol, 58, pp. 1137-1149.

76. Murthy, P.L.N., Chamis, C.C., 1986, Integrated composite analyzer (ICAN), Users and Programmers Manual. NASA Technical Paper 2515, Lewis Research center, Cleveland, $\mathrm{OH}$.

77. Gotsis, P.K., Chamis, C.C., Minnetyan, L., 2002, Application of progressive fracture analysis for predicting failure envelopes and stress-strain behaviors of composite laminates: a comparison with experimental results, Compos Sci Technol, 62, pp. 1545-1559.

78. Chamis, C.C., Abdi, F., Garg, M., Minnetyan, L., Baid, H., Huang, D., Housner, J., Talagani, F., 2013, Micromechanics-based progressive failure analysis prediction for WWFE-III composite coupon test cases, J Compos Mater, 47, pp. 2695-2712.

79. Rosen, B.W., 1964, Tensile failure of fibrous composites, AIAA J, 2(11), pp. 1985-1991.

80. Zweben, C., 1972, A bounding approach to the strength of composite materials, Eng Fracture Mech, 4, pp. 1-8.

81. Curtin, W.A., 1991, Theory of mechanical properties of ceramic-matrix composites, J Am Ceram Soc, 74, pp. 2837-2845.

82. Koyanagi, J., Hatta, H., Kotani, M., Kawada, H., 2009, A comprehensive model for determining tensile strengths of various unidirectional composites, J Compos Mater, 43, pp. 1901-1914.

83. Lamon, J., 2010, Stochastic models of fragmentation of brittle fibers or matrix in composites, Compos Sci Technol, 70, pp. 743-751.

84. Dow, N.F., Rosen, B.W., 1965, Evaluations of filament-reinforced composites for aerospace structural applications, Washington DC: NASA CR-207.

85. Xu, Y.L., Reifsnider, K.L., 1993, Micromechanical modeling of composite compressive strength, J Compos Mater, 27, pp. 572-588.

86. Lo, K.H., Chim, E.S.-M., 1992, Compressive strength of unidirectional composites, J Reinf Plast Compos, 11, pp. 383-396.

87. Budiansky, B., Fleck, N., 1993, Compressive failure of fiber composites, J Mech Phys Solids, 41, pp. $183-211$.

88. Kyriakides, S., Arseculeratne, R., Perry, E.J., Liechti, K.M., 1995, On the compressive failure of fiber reinforced composites, Int J Solids Struct, 32, pp. 689-738. 
89. Jensen, H.M., Christoffersen, J., 1997, Kink band formation in fiber reinforced materials, J Mech Phys Solids, 45, pp. 1121-1136.

90. Ataabadi, A.K., Ziari-Rad, S., Hosseini-Toudeshky, H., 2011, An improved model for fiber kinking analysis of unidirectional laminated composites, Appl Compos Mater, 18, pp. 175-196.

91. Ataabadi, A.K., Hosseini-Toudeshky, H., Rad, S.Z., 2014, Experimental and analytical study on fiberkinking failure mode of laminated composites, Compos B, 61, pp. 84-93.

92. Gutkin, R., Pinho, S.T., Robinson, P., Curtis, P.T., 2010, Micro-mechanical modelling of shear-driven fibre compressive failure and of fibre kinking for failure envelope generation in CFRP laminates, Compos Sci Technol, 70, pp.1214-1222.

93. Gutkin, R., Pinho, S.T., Robinson, P., Curtis, P.T., 2010, On the transition from shear-driven fibre compressive failure to fibre kinking in notched CFRP laminates under longitudinal compression, Compos Sci Technol, 70, pp. 1223-1231.

94. Prabhakar, P., Waas, A.M., 2013, Interaction between kinking and splitting in the compressive failure of unidirectional fiber reinforced laminated composites, Compos Struct, 98, pp. 85-92.

95. Prabhakar, P., Waas, A.M., 2013, Micromechanical modeling to determine the compressive strength and failure mode interaction of multidirectional laminates, Compos A, 50, pp. 11-21.

96. Mishra, A., Naik, N.K., 2009, Inverse micromechanical models for compressive strength of unidirectional composites, J Compos Mater, 43, pp. 1199-1211.

97. Martinez, X., Oller, S., 2009, Numerical simulation of matrix reinforced composite materials subjected to compression loads, Arch Comput Methods Eng, 16, pp. 357-397.

98. Dharan, C.K.H., Lin C-L., 2007, Longitudinal compressive strength of continuous fiber composites, J Compos Mater, 41, pp. 1389-1405.

99. Zidek, R.A.E., Völlmecke, C., 2014, Analytical studies on the imperfection sensitivity and on the kink band inclination angle of unidirectional fiber composites, Compos A, 64, pp. 177-184.

100. Wadee, M.A., Völlmecke, C., Haley J.F., Yiatros, S., 2012, Geometric modelling of kink banding in laminated structures, Philos Trans R Soc A, 370, pp. 1827-1849.

101. Asp, L.E., Berglund, L.A., Talreja, R., 1996, Effect of fiber and interphase on matrix-initiated transverse failure in polymer composites, Compos Sci Technol, 56, pp. 651-665.

102. Asp, L.E., Berglund, L.A., Talreja, R., 1996, Prediction of matrix-initiated transverse failure in polymer composites, Compos Sci Technol, 56, pp. 1089-1097.

103. Carvelli, V., Corigliano, A., 2004, Transverse resistance of long-fibre composites: influence of the fibre-matrix interface, Proceedings of the 11th European conference on composite materials ECCM11, Rhodes, Greece, May 31-June 3, 2004.

104. Cid Alfaro, M.V., Suiker, A.S.J., de Borst, R., 2010, Transverse failure behavior of fiber-epoxy systems, J Compos Mater, 44, pp. 1493-1516.

105. Vaughan, T.J., McCarthy, C.T., 2011, Micromechanical modelling of the transverse damage behaviour in fibre reinforced composites, Compos Sci Technol, 71, pp. 388-396.

106. King, T. R., Blackketter, D.M., Walrath, D.E., Adams, D.F., 1992, Micromechanics prediction of the shear strength of carbon fiber/epoxy matrix composites: the influence of the matrix and interface strengths, J Compos Mater, 26, pp. 558-573.

107. Lafarie-Frenot, M.C., Touchard, F., 1994, Comparative inplane shear behavior of long-carbon-fibre composites with thermoset or thermoplastic matrix, Compos Sci Technol, 52: 417-425.

108. Ng, W.H., Salvi, A.G., Waas, A.M., 2010, Characterization of the in-situ non-linear shear response of laminated fiber-reinforced composites, Compos Sci Technol, 70, pp. 1126-1134.

109. Totry, E., Molina-Aldareguía, J.M., González, C., LLorca, J., 2010, Effect of fiber, matrix and interface properties on the in-plane shear deformation of carbon-fiber reinforced composites, Compos Sci Technol, 70, pp.: 970-980.

110. Giannadakis, K., Varna, J., 2014, Analysis of nonlinear shear stress-strain response of unidirectional GF/EP composite, Compos A, 62, pp.67-76.

111. Canal, L.P., Segurado, J., Llorca, J., 2009, Failure surface of epoxy-modified fiber-reinforced composites under transverse tension and out-of-plane shear, Int J Solids Struct, 46, pp. 2265-2274

112. Totry, E., González, C., Llorca, J., 2008, Failure locus of fiber-reinforced composites under transverse compression and out-of-plane shear, Compos Sci Technol, 68, pp. 829-839.

113. Totry, E., González, C., Llorca, J., 2008, Prediction of the failure locus of C/PEEK composites under transverse compression and longitudinal shear through computational micromechanics, Compos Sci Technol, 68, pp.3128-3136. 
114. Ha, S.K., Jin, K.K., Huang, Y., 2008, Micro-mechanics of failure (MMF) for continuous fiber reinforced composites, J Compos Mater, 42, pp. 1873-1895.

115. Huang, Y., Xu, L., Ha, S.K., 2012, Prediction of three-dimensional composite laminate response using micromechanics of failure, J Compos Mater, 46, pp. 2431-2442.

116. Huang, Y., Jin, C., Ha, S.K., 2013, Strength prediction of triaxially loaded composites using a progressive damage model based on micromechanics of failure, J Compos Mater, 47, pp. 777-792.

117. Melro, A.R., Camanho, P.P., Andrade Pires, F.M., Pinho, S.T., 2013, Micromechanical analysis of polymer composites reinforced by unidirectional fibres: Part I - constitutive modelling, Int J Solids Struct, 50, pp. 1897-1905.

118. Melro, A.R., Camanho, P.P., Andrade Pires, F.M., Pinho, S.T., 2013, Micromechanical analysis of polymer composites reinforced by unidirectional fibres: Part II - micromechanical analyses, Int J Solids Struct, 50. pp. 1906-1915.

119. Talreja, R., 2014, Assessment of the fundamentals of failure theories for composite materials, Compos Sci Technol, 105, pp. 190-201.

120. Chowdhury, N.T., Wang, J., Chiu, W.K., Yan, W., 2016, Predicting matrix failure in composite structures using a hybrid failure criterion, Compos Struct, 137, pp. 148-158. 